Research Article

\title{
Multiobjective Decision-Making for Technical Characteristics Selection in a House of Quality
}

\author{
Jianmin Xie, Qin Qin (D), and Maoting Jiang \\ Department of Economic Management, Southwest University of Science and Technology, Mianyang 621010, China \\ Correspondence should be addressed to Qin Qin; 18281583381@163.com
}

Received 8 December 2019; Revised 21 February 2020; Accepted 22 February 2020; Published 29 April 2020

Academic Editor: Sri Sridharan

Copyright (๑) 2020 Jianmin Xie et al. This is an open access article distributed under the Creative Commons Attribution License, which permits unrestricted use, distribution, and reproduction in any medium, provided the original work is properly cited.

Technical characteristics are an important influencing factor in fuzzy front-end of product innovation design and also an important output of the house of quality. The analysis and decision-making of technical characteristics are conducive to the rational allocation of resources according to their own advantages and the design of products in line with market demand. In view of the multiple objective constraints and internal fuzziness of technical property selection in the house of quality, the traditional methods have great limitations on the decision-making of technical property. Therefore, this paper proposes a multiobjective decision-making method for technical property selection in the house of quality, which aims to calculate and modify the basic importance of technical property. Based on the rough set algorithm, the basic importance of technical characteristics is determined by using the correlation matrix between consumer demand and technical characteristics, and the relative weight of multiple objectives is determined by "least squares." On this basis, the multiobjective decision-making model of technical characteristic selection is established and calculated. At last, an example of mobile phone product design was used to verify the practicability and effectiveness of the method.

\section{Introduction}

Nowadays, the needs and tastes of the market are rapidly changing. In order to survive in a competitive environment, the organizations need to adopt the principles of sustainable development. This means that organizations need to develop innovative products [1]. In product innovation design, its first and crucial stage is the fuzzy front-end (FFE) design. Due to uncertain and fuzzy factors such as consumer demand, technical characteristics, and technical conflicts at this stage, fuzzy front-end design is usually the most important link in the entire product innovation process. Therefore, both industry and academia attach great importance to this stage of research.

The ultimate goal of product innovation design is how to design products that respond to the needs of consumers. Technical characteristics are the basis and guarantee to achieve this goal [2], which can transform consumer demand into technical language. From the current research point of view, the complexity of products is getting higher.
At the same time, the customer demand changes greatly. The traditional technical characteristic decision-making method lacks accuracy and objectivity. There are two main points: (1) the information domain of customers and designers is different, and the needs expressed by customers cannot be accurately mapped into the design specifications; (2) in the face of technical characteristics involving multiple factors [3]. Unfortunately, there is no good decision-making method. In general, the decision-making analysis of consumer demands and technical characteristics in the fuzzy front-end stage is conducive to improving the product innovation and design ability of enterprises and also has important theoretical and practical significance for improving the core competitiveness of enterprises.

Prompt development of new products can be obtained through the quality function deployment (QFD) process, which is critical for companies' survival [4].The house of quality (HOQ) is the core tool of quality function deployment (QFD), and it is also an intuitive form of matrix expression. Customer needs are regarded as WHATs and are 
given to the left side of the HOQ diagram. Of all the features of a product, the key design attributes that the target group values most should be identified [5]. Technical measures, also known as HOWs, comprise the major techniques involved in the production. Considering that many techniques should be carefully associated, excluded, or revised, at least 10 technical characteristics should be adequate as technical measures in a HOQ diagram [6]. Technical characteristics are the ceiling part of $\mathrm{HOQ}$, and the correlation matrix of technical characteristics and consumer requirements constitutes the HOQ room. The decision of technical characteristics and consumer need is two complementary processes, and the technical characteristics are the basis and guarantee to realize and meet consumer needs. According to the idea of $\mathrm{HOQ}$, by establishing the consumer demand matrix, the correlation matrix between consumer demand and technical characteristics and the autocorrelation matrix of technical characteristics, it is possible to effectively analyze and make decisions on consumer requirements and technical characteristics in the fuzzy front-end stage [7]. Like consumer demand, technical characteristics are also highly ambiguous, and they are also an important influencing factor for fuzzy front-end design of products. In addition, the importance of technical characteristics is also an important output of HOQ. Therefore, the correct establishment of the mapping relationship between consumer demand and technical characteristics is conducive for enterprises to make reasonable resource allocation based on their own advantages. And analyzing and deciding on the technical characteristics are conducive for enterprises to make reasonable resource allocation based on their own advantages and design products that meet market demand.

In short, although many methods have been used to calculate the importance of technical characteristics, there are often many technical characteristics when dealing with complex and huge product designs, and the application of these methods will have certain limitations. In addition, when making decision analysis on technical characteristics, most scholars only consider a single factor which makes the decision and analysis inaccurate. Motivated by the above reasons, this paper studies the problem of technical characteristic decision-making. The main contributions of this paper are summarized as follows:

(1) In order to improve the accuracy of the basic importance of technical characteristics, this paper proposes a method to calculate and modify the importance of technical characteristics

(2) This method can use the rough set algorithm to establish the correlation matrix between consumer demand and technical characteristics to calculate the basic importance of technical characteristics

(3) Using the TOPSIS multiattribute decision-making model, we can modify the basic importance of technical characteristics

The rest of the paper is organized as follows: the literature of the product innovation design is given in Section 2; in Section 3, the basic importance of technical characteristics is calculated; in Section 4, the TOPSIS multiobjective decision model is used to modify the basic importance; in Section 5, the effectiveness of the proposed method is verified by an example of mobile phone product design; the conclusions are given, and we make future research suggestions in Section 6.

\section{Literature Review}

The literature review is focused on three perspectives: (1) the method of product innovation design; (2) the calculation method of technical characteristic importance; (3) TOPSIS multiobjective decision-making.

2.1. Quality Function Deployment. Quality function deployment (QFD) is often used in product innovation, and some scholars give definition of QFD as follows: Lam and Dai stated that "QFD is well known as a system for translating the "voice" of customers into appropriate company requirement" [8]. And, QFD is a useful tool to develop new products which can maximise customers' satisfactions in different product development phases [9]. In addition, it is also a methodology that helps translating customer needs into design requirements to ensure that the output, whether this is a product or process, meets these needs [10].

A number of methods have been proposed in the past decades in order to enhance performance of the standard QFD [11], mainly involved in two main directions for improvement. On the one hand, use MCDM methods to handle the uncertainty in the conventional QFD process [12]. Others are multiobjective optimization based on ratio analysis (MOORA) [13] and technique for order preference by similarity to the ideal solution (TOPSIS) [14]. And some researchers have enriched QFD by working on linguistic numeric scales, while others have introduced hybrid approaches to enhance the reliability of results. Furthermore, some provided an enhanced version of QFD that captures customers present and future preferences, accurately prioritizes product specifications, and eventually translates them into desirable quality products [15]. On the other hand, by synthesizing additional methods, such as fuzzy theory [16], rough theory, and interval valued fuzzy rough set [17], some scholars also improved QFD. All these methods are dedicated to improve the reliability of QFD.

Some scholars have also proposed many methods of product innovation design. For example, Vinodh et al. proposed to integrate QFD, TRIZ, and AHP for innovative and sustainable product development, where AHP is used to evaluate and determine the most suitable design [18]. Besides, an integrated framework based on the GRA method and ANP approach is proposed to determine the important degrees of product technical requirements (PTRs) in designing a product [19].

QFD model is commonly used in product innovation design. Its shortcomings are as follows: (1) QFD cannot deal with subjectivity or fuzziness at the same time. The demand for prior information is large. (2) It cannot overcome small sample error and cannot reveal internal correlation. Then, 
many product innovation methods are constantly improved, and some models are proposed. Based on the house of quality in QFD theory, this paper also makes a series of calculations on technical characteristics.

\subsection{Calculation Method of the Importance of Technical} Characteristics. Technical characteristics refer to the conversion of consumer-written requirements into technical languages, which can make abstract consumer requirements into specific products. Thus, the important calculation of technical characteristics is an important part of HOQ construction and an important output of $\mathrm{HOQ}$.

\subsubsection{Sorting Method of Technical Characteristics. Iqbal used} QFD to enhance the prioritisation of technical characteristics (TAs). Wang proposed the method of combining subjective and objective weights to determine the weights of customer requirements (CRs) and technical characteristics (TAs), in which subjective factors were considered in the qualitative judgment of experts [4].

2.2.2. Analytic Network Process (ANP). At present, the academia generally uses analytic network process (ANP), fuzzy logic reasoning, and other methods to calculate the existing importance of technical characteristics [20]. Lam and Lai and others transform customer demand into functional demand based on the ANP-QFD model and determine the importance of functional demand. However, there is a big deviation in using a 1-9 scale method to evaluate the relationship between various parts of the house of quality [21]. Zaim et al. proposed a hybrid analytic network process (ANP) weighted fuzzy methodology. The goal is to synthesize renowned capabilities of ANP and fuzzy logic to better rank technical characteristics of a product (or a service) while implementing QFD [22]. ANP itself has great drawbacks, and it will cause the construction of the judgment matrix showing an increase in geometric multiples when the index in the network that needs to be analyzed is increased, and for judgment matrix, the exact calculation of eigenvalues and eigenvectors is complicated. Technical characteristics tend to be more in complex product design, and ANP has great application limitations.

\subsubsection{The Correlation Matrix between Consumer Demand} and Technical Characteristics. As the technical characteristics are determined by the consumer demand, the traditional method to establish the correlation matrix between consumer demand and technical characteristics is the project implementation staffs determining the relationship between the two through experience. For example, SangBing et al. used DEMATEL to analyze the causal relationship between the technical characteristics of customer demand surplus and classify it into causal categories [23]; Park and Kim proposed a swing algorithm to establish the correlation matrix between the two and believed should make full use of the experience and knowledge of project implementation staffs in the process of determining the correlation matrix
[24]. These methods result in large errors for the existence of subjectivity. Aiming at the intrinsic fuzziness of the relationship between the two, some documents use the fuzzy regression model to establish the correlation matrix between the two. Kim et al. proposed to use fuzzy multiattribute value theory and fuzzy regression and fuzzy optimization theory to establish the correlation matrix between the two [25]; Fung et al. integrated the least squares method into the fuzzy regression model and proposed two mixed asymmetric fuzzy linear programming model to determine the relationship between the two [26]. Though the use of fuzzy algorithm can characterize the fuzzy relationship between the two and needs to prebuilt degree of membership function, the process of building degree of membership function is more dependent on experience, which also affects the objectivity of establishing the correlation matrix between the two. Training sample sets depends too much on the QFD team's experience and knowledge, which may lead to the final result, and is not objective enough.

2.2.4. Fuzzy Sets Theory and Rough Set Theory. Due to the uncertainty and fuzziness of human perception and judgment, according to the fuzzy relationship between cognitive system, fuzzy evaluation is widely used to obtain the importance of cognitive system [27].

First, many scholars use fuzzy set theory to calculate engineering characteristics in process innovation design. Considering the imprecise information in the design stage, fuzzy set theory is employed to develop fuzzy approaches for constructing the HOQ [28]. Wong et al. suggested a fuzzy approach to determine the aggregated importance weights of ECs through fuzzy expert systems in QFD [29]. Liu et al. put forward an approach to get the exact expected values and rank the importance of ECs in fuzzy QFD environments [30]. In order to overcome the subjectivity of fuzzy membership function selection, some proposed a fuzzy axiomatic design method based on rough set to guide the design decision-making process with inaccurate information [31]. Then, many scholars use fuzzy sets theory to calculate the importance of technical characteristics. For example, Song et al. calculate the importance of CR and the priority of technical characteristics based on the hybrid method of rough set theory (RST) and grey relational analysis (GRA) [32], Karsak uses fuzzy multiobjective decision-making to rank the importance of technical characteristics in the process of product planning [33], and some documents use fuzzy sets to construct different models to sort technical characteristics [34-36]. To a certain extent, fuzzy sets solve the ambiguity and uncertainty of technical characteristics, but it needs to build degree of membership function, the demand for this prior knowledge has led to inaccurate decision-making of technical characteristics, and the construction of degree of membership function is often more difficult; therefore, there is a big problem with the use of fuzzy sets theory in making decisions about technical characteristics.

Then, compared with fuzzy set theory, rough set theory can be applicable to a much wider variety of design problems 
[37]. Rough set theory is an algorithm which deals with an impreciseness and lack of certainty based on decisionmaking [38]. The correlation measure matrix corresponding to each customer requirements can be identified with the assistance of intelligent characteristics of a rough set [39]. By means of binary relations, two definable sets, i.e., lower and upper approximations, can be designed for constructing a classical rough set [40]. Rough set is for rating customer requirements' final importance. Similarly, we can also use it in the calculation of the basic importance of the technical characteristics of product innovation design. One of the demerits of rough set theory is its dependence on complete information systems; i.e., a decision table to be processed must be complete, and all objects' values must be known. Some studies develop Bayesian rough set model to handle demerits of rough set. Bayesian rough set model proposes probability approximation [41].

Thus, rough set is more widely used than the fuzzy set. It can effectively analyze imprecise, inconsistent, incomplete, and other information. Rough set algorithm is used to establish the correlation matrix between consumer demand and technical characteristics in this paper.

2.3. Technique for Order Preference by Similarity to Ideal Solution (TOPSIS). Multicriteria decision-making can be defined as the evaluation of the alternatives for the purpose of selection or ranking, using a number of qualitative and/or quantitative criteria that have different measurement units. To this end, in the context of decision theory, ELECTRE, AHP, fuzzy, ANP and TOPSIS can be sorted as primary methods [42]. The Technique for Order Preference by Similarity to Ideal Solution (TOPSIS) was first put forward by Hwang and Yoon in 1981 [43]. TOPSIS is an effective method for solving problems existing in multiattribute decision-making with finite alternatives [44]. The TOPSIS method is mostly employed to optimize process parameters. TOPSIS combines quantifiable factors such as cost, time, and distance with qualitative factors such as quality assurance and reliability and compares all alternatives together based on these factors [45]. Dwivedi and Srivastava have modified the closeness coefficient by incorporating a set of weights associated with the distance from the positive and negative ideal solutions [46].

Moreover, there are other experts and scholars who use other methods to study the decision of technical characteristics, Tang et al. aim to maximise consumer satisfaction and builds an integer programming model to determine the optimal configuration of technical characteristics in HOQ [47]. Jaeho et al. have developed a network system based on QFD-TOPSIS logic. User preferences of building technology, products, systems, design schemes, and other alternatives are proposed, and the technical characteristics of the house of quality are determined [48]. Liao and Kao obtained the weight of customer demand by establishing two-to-two comparison matrix in the analytic hierarchy process and analyzing the importance of the fuzzy hierarchy matrix and then analyzed its technical characteristics [49]. When analyzing and deciding on technical characteristics, these methods only consider the factors of consumer demand and do not consider other factors such as research and development time and economic investment in innovative design process.

On comprehensive analysis of the above scholars' research results, this paper presents a method of ranking the importance of technical characteristics in the process of product innovation design. First, based on consumer demand, establish the correlation matrix between consumer demand and technical characteristics to calculate the basic importance of technical characteristics by the rough set algorithm. Second, establish the TOPSIS multiattribute decision-making model and introduce the evaluation of the technical characteristics of competitiveness to amend the basic importance, for the importance of technical characteristics is determined by a combination of multiple factors. Finally, through a mobile phone product design example, we verified the effectiveness of the proposed method. The specific method flow of this paper is shown in Figure 1.

\section{Calculation of the Basic Importance of Technical Characteristics}

Consumer demand is the basis and premise of decisionmaking of technical characteristics. The basic importance of technical characteristics proposed in this section is calculated by establishing the correlation matrix between consumer demand and technical characteristics. The correlation matrix of consumer demand and technical characteristics is also an important part of HOQ.

Use rough sets to calculate the basic importance of technical characteristics' steps as follows [50]:

Step 1. Build technical characteristics hierarchy.

Use the affinity diagram (KJ) method to cluster the acquired technical characteristics into a hierarchical structure of technical characteristics.

Step 2. Technical characteristics survey.

To determine the importance of technical characteristics, the main targets of the survey were engineering designers, and the combination of different technical characteristics of the composition of the impact on consumer demand needs to be investigated.

Step 3. Build a decision table $(M)$ complying with the rough set definition:

$$
M=\left[U, A^{\mathrm{TC}} U B^{\mathrm{CR}}\right] .
$$

The combination of the strengths and weaknesses of different technical characteristics constitutes the object $(U)$; the set of technical characteristics $\left(A^{\mathrm{TC}}=\left[\mathrm{TC}_{1}, \mathrm{TC}_{2}, \mathrm{LTC}_{m}\right]\right)$ represents the condition attribute sets; customer requirements (CRs) represent the decision $A$ attribute sets $\left(B^{R}=[\mathrm{CR}]\right)$; the result of the second step is the property value, among them, and represents the attribute set of technical characteristics; and $B$ represents the attribute set of consumer demand and to form a decision system.

Step 4. Determine whether technical characteristics can be reduced. 


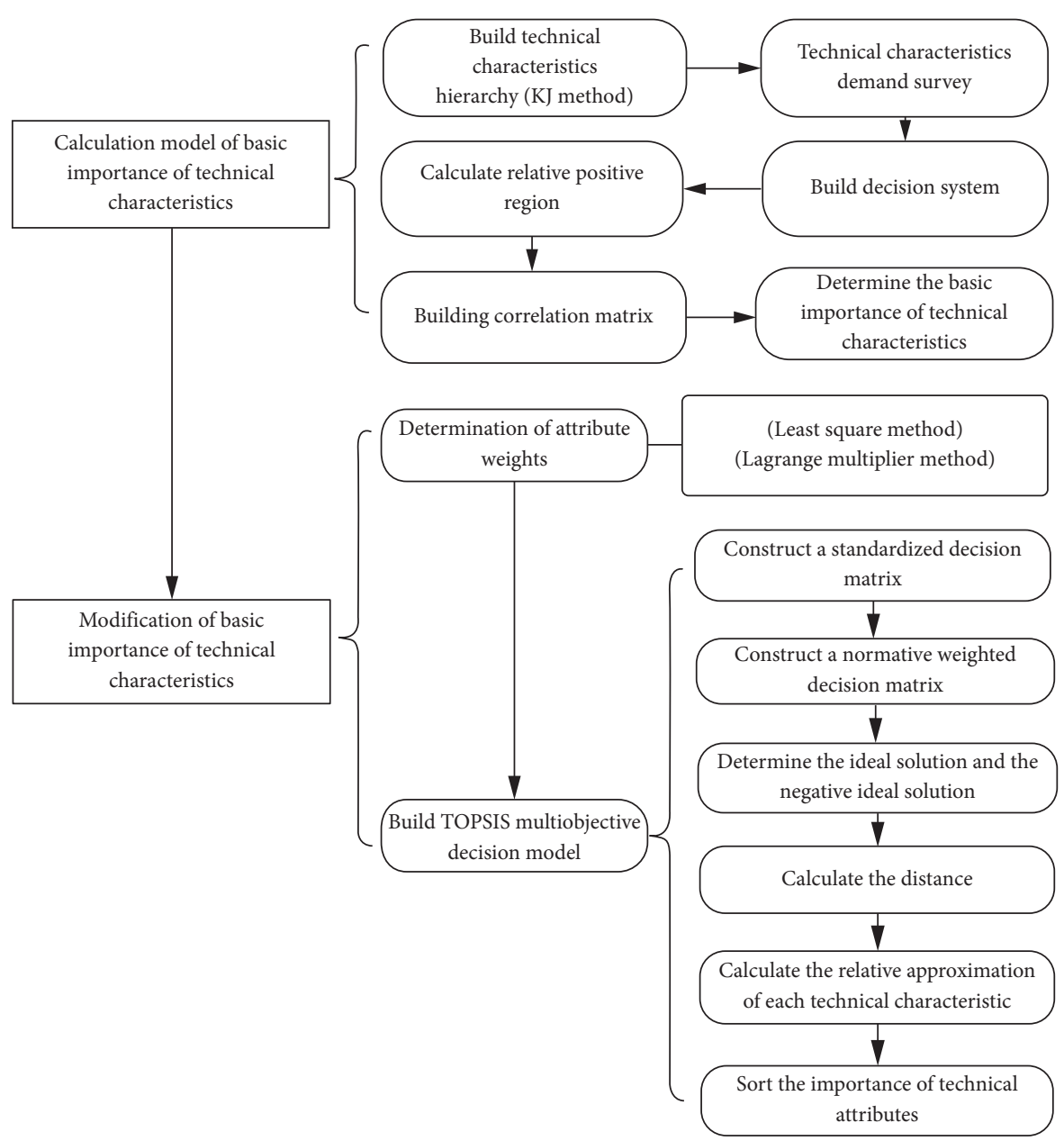

Figure 1: A flowchart for methodology.

According to the relative positive domain definition, by calculating whether $\operatorname{POS}_{A}(B)$ is equal to $\underset{A-\left\{\mathrm{TC}_{i}\right\}}{\operatorname{POS}(B)}$ to determine whether each requirement can be reduced. If it indicates that the technical characteristic $\left(\mathrm{TC}_{i}\right)$ can be reduced relative to the customer requirements $(\mathrm{CR})$, in other words, the contribution of the technical characteristic $\left(\mathrm{TC}_{i}\right)$ to the customer requirements (CR) is zero, and there is no relationship between the two. On the contrary, if $\operatorname{POS}_{A} B \neq \begin{aligned} & \operatorname{POS}(B) \\ & A-\left\{\mathrm{TC}_{i}\right\}\end{aligned}$, it shows that the technical characteristic $\left(\mathrm{TC}_{i}\right)$ is irreducible and relative to the customer requirements (CRs), indicating that the two are related.

Step 5. Calculate the correlation between consumer demand and technical characteristics.

$\varepsilon_{i j}$ is used to indicate the correlation between the customer requirement $\left(\mathrm{CR}_{i}\right)$ and the technical characteristic $\left(\mathrm{TC}_{j}\right)$ :

$$
\varepsilon_{i j}=\frac{\left|\operatorname{POS}_{A} B\right|}{|U|}-\frac{\operatorname{POS}(B)}{\mid U-\left\{\mathrm{CR}_{i j}\right\}} .
$$

Step 6. Construct a correlation matrix (RM) between consumer demand and technical characteristics:

$$
\mathrm{RM}=\left(\varepsilon_{i j}\right)_{j=1 \mathrm{Lm}}^{i=1 \mathrm{Ln}} .
$$

Step 7. According to the correlation matrix $(R M)$ to determine the fundamental importance of the technical characteristics $(\beta)$,

$$
\beta_{i}=\frac{\sum_{j=1}^{n} \varepsilon_{i j}}{n} .
$$

\section{TOPSIS Multiobjective Decision-Making Model to Amend the Fundamental Importance}

Optimization of technical characteristics is not only affected by consumer demand, but also by research and development (R\&D) time, R\&D investment funds, human resources consumption, and other factors, so the problem is a multiattribute decision-making problem.

4.1. Determination of Attribute Weights. Suppose that there are $n$ factors who affect the decision of technical 
characteristics; note that $w_{i}$ is the weight of the $i$ influencing factor and $\alpha_{i j}$ represents the weight of the $i$ attribute relative to the $j$ attribute; and the result of pairwise comparison of $n$ factors is matrix $(M)$ :

$$
M=\left[\begin{array}{cccc}
a_{11} & a_{12} & L & a_{1 n} \\
a_{21} & a_{22} & L & a_{2 n} \\
M & M & M & M \\
a_{n 1} & a_{n 2} & L & a_{n n}
\end{array}\right] .
$$

If policymakers can accurately estimate the ratio of any two influential factors weight, then

$$
w_{i}=\frac{\sum_{j=1}^{n} w_{j}}{\sum_{j=1}^{n} a_{i j}}=\frac{1}{\sum_{j=1}^{n} a_{i j}} .
$$

If policymakers' estimation of the ratio of any two influential factors to weight is inaccurate, the least square method can be used to determine the weight of each attribute, to solve the following:

$$
\min \left\{\sum_{j=1}^{n} \sum_{j=1}^{n}\left(a_{i j} w_{j}-w_{i}\right)^{2}\right\} \text {. }
$$

Constraint condition:

$$
\sum_{i=1}^{n} w i=1, \quad w_{i}>0
$$

Use Lagrange multiplier method to get the weight of each attribute. The Lagrange function is

$$
\mathrm{L}=\sum_{i=1}^{n} \sum_{j=1}^{n}\left(a_{i j} w_{j}-w_{i}\right)^{2}+2 \lambda\left(\sum_{i} w_{i}-1\right) .
$$

Seeking partial derivative of $w_{l}$ and making it zero, it can get $n$ algebraic equations; let $\sum_{i=1}^{n} w_{i}=1$, then get $n+1$ algebraic equations. Because $w_{1}, w_{2} L, w_{n}$, and $\lambda$ total $n+1$ variables, the number of equations is equal to the number of variables and then you can find the weight $\left(w_{1}, w_{2} L, w_{n}\right)$ of each attribute.

\subsection{Construct TOPSIS Multiobjective Decision Model.} TOPSIS is a common method of decision-making in the analysis of multiattribute decision-making for finite programs, and it aims to choose the optimal solution and minimize the distance between the optimal solution and the positive ideal solution and the longest distance from the negative ideal solution [51]. This method can be used to modify the basic importance of technical characteristics in innovative design, and its algorithm steps are as follows:

Step 1. Construct a standardized decision matrix.

It is assumed that there are $i$ factors that influence the decision of technical characteristics, and each factor has $j$ attribute values; $y_{i j}$ represents the evaluation value of the $i$ factor under the $j$ attribute value, and the decision matrix $Y$ is

$$
Y=\left[\begin{array}{llll}
y_{11} & y_{12} & K & y_{1 j} \\
y_{21} & y_{22} & K & y_{2 j} \\
M & M & M & M \\
y_{i 1} & y_{i 2} & K & y_{i j}
\end{array}\right] .
$$

Let $z_{i j}$ be the normalized evaluation value, and there is

$$
z_{i j}=\frac{y_{i j}}{\sqrt{\sum_{i=1}^{m} y_{i j}^{2}}} \text {. }
$$

Obtain a normative decision matrix $Z$ :

$$
Z=\left[\begin{array}{llll}
z_{11} & z_{12} & K & z_{1 j} \\
z_{21} & z_{22} & K & z_{2 j} \\
M & M & M & M \\
z_{i 1} & z_{i 2} & K & z_{i j}
\end{array}\right]
$$

Step 2. Construct a normative weighted decision matrix. Suppose the weighted normative matrix is defined as $X=\left\{x_{i j}\right\}$, the method proposed in Section 4.1 gives relative weight matrix $w=w=\left(w_{1}, w_{2} L, w_{n}\right)^{T}$ for each attribute, and there is

$$
x_{i j}=w_{j} \times z_{i j}, \quad i=1,2 \mathrm{Lm} ; j=1,2 \mathrm{Ln} .
$$

Step 3. Determine the ideal solution and the negative ideal solution.

Let the $i$ attribute values of positive ideal solution $\left(x^{+}\right)$ be $x_{i}^{+}$, and the $i$ attribute values of negative ideal solution $\left(x^{-}\right)$be $x_{i}^{-}$, and there is

$x_{i}^{+}=\left\{\left(\begin{array}{c}\max x_{i j} \\ j\end{array} \mid j \in B\right),\left(\begin{array}{c}\min x_{i j} \\ j\end{array} \mid j \in C\right) \mid j=1,2, \ldots, n\right\}$,

$$
x_{i}^{-}=\left\{\left(\begin{array}{c}
\max x_{i j} \\
j
\end{array} \mid j \in B\right),\left(\begin{array}{c}
\min x_{i j} \\
j
\end{array} \mid j \in C\right) \mid j=1,2, \ldots, n\right\} .
$$

Among them, $B$ is a collection of efficiency-based attributes, and $C$ is a collection of cost-based attributes.

Step 4. Calculate the distance between each factor and ideal solution and negative ideal solution.

The distance to the ideal solution is indicated by $d_{i}^{+}$, and the distance to the negative ideal solution is indicated by $d_{i}^{-}$:

$$
\begin{aligned}
& d_{i}^{+}=\sqrt{\sum_{j=1}^{n}\left(x_{i j}-x_{j}^{+}\right)^{2}}, \quad i=1,2, \ldots, m, \\
& d_{i}^{-}=\sqrt{\sum_{j=1}^{n}\left(x_{i j}-x_{j}^{-}\right)^{2}}, \quad i=1,2, \ldots, m .
\end{aligned}
$$

Step 5. Calculate the relative approximation of each technical characteristic. 
The sorting of technical characteristics must also consider the distance from positive and negative ideal solutions; let $C_{i}^{*}$ denote the relative approximate value of the $i$ technical characteristic's distance to the ideal solution, and there is

$$
C_{i}^{*}=\frac{d_{i}^{-}}{d_{i}^{-}+d_{i}^{+}}, \quad i=1,2 \mathrm{Lm} .
$$

Step 6. According to $C_{i}^{*}$, sort the importance of technical characteristics by descending order.

\section{Case Analysis}

Taking a mobile phone product developed by an enterprise as an example to verify the importance of ranking method of technical characteristics proposed in this chapter. According to the method proposed in this paper, the final importance of technical characteristics is obtained from the basic importance and the modification of the basic importance.

\subsection{Calculate the Basic Importance of Technical Characteristics}

Step 1. Get and analyze technical characteristics.

The company decided to improve existing products in terms of three consumer needs: good texture, more color choices, and good texture. These three consumer demands form the set of consumer demand to be improved $\mathrm{CR}=\left[\right.$ call clear $\left(\mathrm{CR}_{1}\right)$, good texture $\left(\mathrm{CR}_{2}\right)$, responsive $\left.\left(\mathrm{CR}_{3}\right)\right]$. Then, the company holds a brainstorming session and gets a collection of technical characteristics after analyzing and processing $\mathrm{TC}=$ [shell material $\left(\mathrm{TC}_{1}\right)$, processor performance $\left(\mathrm{TC}_{2}\right)$, operating system performance $\left.\left(\mathrm{TC}_{3}\right)\right]$.

Step 2. Technical characteristics survey.

Set consumer satisfaction assessment sets as $v=\left\{v_{1}, v_{2}, v_{3}\right\}$; the value of each element is $v_{1}=1$, $v_{2}=2$, and $v_{3}=3$; and the corresponding evaluation result is $v=$ \{unsatisfied, generally satisfied, satisfied \}. Then, discretization of the technical characteristics is shown in Table 1.

Select the appropriate engineering design staff for the survey, and what needs to be investigated is to determine the extent to which consumer demand is fulfilled with different combinations of technical characteristics.

Step 3. Build a decision system.

It is up to the consumer demand to determine three sets of condition attributes $A_{i}=\left(\mathrm{CR}_{i}\right), i=1,2,3$; technical characteristics form a common set of decision attributes $B=\left(\mathrm{TC}_{1}, \mathrm{TC}_{2}, \mathrm{TC}_{3}\right)$, and the combination of different technical characteristics constitutes the object $U$; then, three decision-making systems $S_{i}=(U$, $\left.A_{i} \cup B\right), i=1,2,3$, can be established.

According to the above rating, under different grading combinations of technical characteristics, record the rating of the consumer demand and, respectively, build different consumer demand decision tables. Call clear $\left(\mathrm{CR}_{1}\right)$ decision table, as shown in Table 2, and similarly, get good texture $\left(\mathrm{CR}_{2}\right)$ decision table, as shown in Table 3, and responsive $\left(\mathrm{CR}_{3}\right)$ decision table, as shown in Table 4 .

Step 4. Determine whether technical characteristics can be reduced relative to consumer demand.

Target at consumer demand "call clear $\left(\mathrm{CR}_{1}\right)$," and according to relative positive domain definition, it can separately obtain the relative positive region of each technical characteristic relative to the consumer demand "call clear $\left(\mathrm{CR}_{1}\right)$." The relative positive region of shell material $\left(\mathrm{TC}_{1}\right)$ is

$$
\begin{aligned}
\underset{A_{1}\left\{\mathrm{TC}_{2}\right\}}{\operatorname{POS}(B)_{1}=} & \left\{\left\{U_{1}, U_{10}, U_{19}\right\},\left\{U_{2}, U_{11}, U_{20}\right\},\left\{U_{3}, U_{12}\right\},\right. \\
& \left\{U_{4}, U_{13}\right\}\left\{U_{5}, U_{14}\right\},\left\{U_{6}, U_{15}\right\}, \\
& \left\{U_{7}, U_{16}, U_{25}\right\},\left\{U_{8}, U_{17}, U_{26}\right\}, \\
& \left.\left\{U_{9}, U_{18}, U_{27}\right\}\right\} .
\end{aligned}
$$

The same can be obtained, and the relative positive region of the processor performance $\left(\mathrm{TC}_{2}\right)$ is

$$
\begin{gathered}
\operatorname{POS}(B)_{A_{1}}=\left\{\left\{U_{1}, U_{4}\right\},\left\{U_{10}, U_{13}\right\},\left\{U_{22}, U_{25}\right\},\right. \\
A_{1}\left\{\mathrm{TC}_{2}\right\} \\
\\
\left.\left\{U_{23}, U_{26}\right\},\left\{U_{24}, U_{27}\right\}\right\} .
\end{gathered}
$$

And the relative positive region of operating system performance $\left(\mathrm{TC}_{3}\right)$ is

$$
\begin{aligned}
\operatorname{POS}(B)_{A_{1}}= & \left\{\left\{U_{1}, U_{2}, U_{3}\right\},\left\{U_{5}, U_{6}\right\},\left\{U_{8}, U_{9}\right\},\right. \\
A_{1}\left\{T C_{3}\right\} & \left\{U_{10}, U_{11}, U_{12}\right\},\left\{U_{14}, U_{15}\right\},\left\{U_{17}, U_{18}\right\}, \\
& \left.\left\{U_{19}, U_{20}\right\},\left\{U_{23}, U_{24}\right\},\left\{U_{26}, U_{27}\right\}\right\} .
\end{aligned}
$$

Because $\quad \operatorname{POS}_{A_{1}}(B) \neq \begin{aligned} & \operatorname{POS}(B)_{A_{1}} \\ & A_{1}-\left\{\mathrm{TC}_{1}\right\}\end{aligned}, \quad \operatorname{POS}_{A_{1}}(B) \neq$ $\operatorname{POS}(B)_{A_{1}}$
$A_{1}-\left\{\mathrm{TC}_{2}\right\}$ , and $\operatorname{POS}_{A_{1}}(B) \neq \begin{aligned} & \operatorname{POS}(B)_{A_{1}} \\ & A_{1}-\left\{\mathrm{TC}_{3}\right\}\end{aligned}$, the technical characteristic $\left(\mathrm{TC}_{1}, \mathrm{TC}_{2}\right.$, and $\left.\mathrm{TC}_{3}\right)$ is irreducible relative to the customer requirements $\left(\mathrm{CR}_{1}\right)$, indicating that there is an association between technical characteristics and consumer demand.

Similarly, target at consumer demand "good texture $\left(\mathrm{CR}_{2}\right) ; "$ because $\operatorname{POS}_{A_{2}}(B) \neq \begin{aligned} & \operatorname{POS}(B)_{A_{2}} \\ & A_{2}-\left\{\mathrm{TC}_{1}\right\}\end{aligned}$ and $\operatorname{POS}_{A_{2}}(B) \neq \begin{aligned} & \operatorname{POS}(B)_{A_{2}} \\ & A_{2}-\left\{\mathrm{TC}_{2}\right\}\end{aligned}$, the technical characteristic $\left(\mathrm{TC}_{1}\right.$ and $\left.\mathrm{TC}_{2}\right)$ is irreducible. But for $\operatorname{POS}_{A_{2}}(B) \neq \begin{aligned} & \operatorname{POS}(B)_{A_{2}} \\ & A_{2}-\left\{\mathrm{TC}_{3}\right\}\end{aligned}$, the technical characteristics "operating system performance $\mathrm{TC}_{3}$ " can be reduced relative to consumer demand "good texture $\left(\mathrm{CR}_{2}\right)$," and this shows that $\mathrm{TC}_{3}$ and $\mathrm{CR}_{2}$ are not related. 
TABLE 1: Technical characteristics rating.

\begin{tabular}{lcc}
\hline Serial number & Technical characteristics & Rating \\
\hline $\mathrm{TC}_{1}$ & Shell material & Strong 1, general 2, week 3 \\
$\mathrm{TC}_{2}$ & Processor performance & Good 1, general 2, bad 3 \\
$\mathrm{TC}_{3}$ & Operating system performance & Good 1, general 2, bad 3 \\
\hline
\end{tabular}

TABLE 2: Call clear $\left(\mathrm{CR}_{1}\right)$ decision table.

\begin{tabular}{cccccccccccccccc}
\hline$U$ & $\mathrm{TC}_{1}$ & $\mathrm{TC}_{2}$ & $\mathrm{TC}_{3}$ & $\mathrm{CR}_{1}$ & $U$ & $\mathrm{TC}_{1}$ & $\mathrm{TC}_{2}$ & $\mathrm{TC}_{3}$ & $\mathrm{CR}_{1}$ & $U$ & $\mathrm{TC}_{1}$ & $\mathrm{TC}_{2}$ & $\mathrm{TC}_{3}$ & $\mathrm{CR}_{1}$ \\
\hline 1 & 1 & 1 & 1 & 1 & 10 & 2 & 1 & 1 & 1 & 19 & 3 & 1 & 1 \\
2 & 1 & 1 & 2 & 1 & 11 & 2 & 1 & 2 & 1 & 20 & 3 & 1 & 2 & 1 \\
3 & 1 & 1 & 3 & 1 & 12 & 2 & 1 & 3 & 1 & 21 & 3 & 1 & 3 & 2 \\
4 & 1 & 2 & 1 & 1 & 13 & 2 & 2 & 1 & 1 & 22 & 3 & 2 & 1 & 2 \\
5 & 1 & 2 & 2 & 2 & 14 & 2 & 2 & 2 & 2 & 23 & 3 & 2 & 2 & 3 \\
6 & 1 & 2 & 3 & 2 & 15 & 2 & 2 & 3 & 2 & 24 & 3 & 2 & 3 \\
7 & 1 & 3 & 1 & 2 & 16 & 2 & 3 & 1 & 2 & 25 & 3 & 3 & 1 & 2 \\
8 & 1 & 3 & 2 & 3 & 17 & 2 & 3 & 2 & 3 & 26 & 3 & 3 & 2 & 3 \\
9 & 1 & 3 & 3 & 3 & 18 & 2 & 3 & 3 & 3 & 27 & 3 & 3 & 3 \\
\hline
\end{tabular}

Target at consumer demand "responsive $\left(\mathrm{CR}_{3}\right)$;" because $\quad \operatorname{POS}_{A_{3}}(B) \neq \begin{aligned} & \operatorname{POS}(B)_{A_{3}} \\ & A_{3}-\left\{\mathrm{TC}_{1}\right\}\end{aligned}, \quad \operatorname{POS}_{A_{3}}(B) \neq$ $\operatorname{POS}(B)_{A_{3}}$
$A_{3}-\left\{\mathrm{TC}_{1}\right\}$ , and $\operatorname{POS}_{A_{3}}(B) \neq \begin{aligned} & \operatorname{POS}(B)_{A_{3}} \\ & A_{3}-\left\{\mathrm{TC}_{1}\right\}\end{aligned}$, the technical characteristics $\left(\mathrm{TC}_{1}\right)$ can be reduced, but the $\mathrm{TC}_{2}$ and $\mathrm{TC}_{3}$ are irreducible.

Step 5. Calculate the degree of correlation of technical characteristics and consumer demand.

According to formula (2), calculate the degree of correlation between technical characteristics $\left(\mathrm{TC}_{1}\right.$, $\mathrm{TC}_{2}$, and $\mathrm{TC}_{3}$ ) and consumer demand $\left(\mathrm{CR}_{1}\right)$, respectively:

$$
\begin{aligned}
& \lambda_{11}=\frac{\left|\operatorname{POS}_{A_{1}}(B)\right|}{|U|}-\frac{\begin{array}{c}
\operatorname{POS}(B) \\
A_{1}\left\{\mathrm{TC}_{1}\right\}
\end{array}}{|U|}=1-\frac{23}{27}=0.148, \\
& \lambda_{12}=\frac{\left|\operatorname{POS}_{A_{1}}(B)\right|}{|U|}-\frac{\begin{array}{c}
\operatorname{POS}(B) \\
A_{1}\left\{\mathrm{TC}_{2}\right\}
\end{array}}{|U|}=1-\frac{10}{27}=0.630, \\
& \lambda_{13}=\frac{\left|\operatorname{POS}_{A_{1}}(B)\right|}{|U|}-\frac{\operatorname{POS}(B)}{|U|}=1-\frac{20}{27}=0.259 .
\end{aligned}
$$

The same can be obtained; the degree of correlation between technical characteristics $\left(\mathrm{TC}_{1}, \mathrm{TC}_{2}\right.$, and $\left.\mathrm{TC}_{3}\right)$ and consumer demand $\left(\mathrm{CR}_{2}\right)$ is

$$
\begin{aligned}
& \lambda_{21}=\frac{\left|\operatorname{POS}_{A_{2}}(B)\right|}{|U|}-\frac{\begin{array}{c}
\operatorname{POS}(B) \\
A_{2}\left\{\mathrm{TC}_{1}\right\}
\end{array}}{|U|}=1-\frac{12}{27}=0.556, \\
& \lambda_{22}=\frac{\left|\operatorname{POS}_{A_{2}}(B)\right|}{|U|}-\frac{\operatorname{POS}(B)}{|U|}=1-\frac{18}{27}=0.333, \\
& \lambda_{23}=\frac{\left.\mid \mathrm{POS}_{2}\right\}}{|U|}-\frac{\operatorname{POS}_{A_{2}}(B) \mid}{|U|}-\frac{A_{2}\left\{\mathrm{TC}_{3}\right\}}{|U|}=1-\frac{27}{27}=0 .
\end{aligned}
$$

The degree of correlation between technical characteristics $\left(\mathrm{TC}_{1}, \mathrm{TC}_{2}\right.$, and $\left.\mathrm{TC}_{3}\right)$ and consumer demand $\left(\mathrm{CR}_{3}\right)$ is

$$
\begin{aligned}
& \lambda_{31}=\frac{\left|\operatorname{POS}_{A_{3}}(B)\right|}{|U|}-\frac{\begin{array}{c}
\operatorname{POS}(B) \\
A_{3}\left\{\mathrm{TC}_{1}\right\}
\end{array}}{|U|}=1-\frac{27}{27}=0, \\
& \lambda_{32}=\frac{\left|\operatorname{POS}_{A_{3}}(B)\right|}{|U|}-\frac{\operatorname{POS}(B)}{|U|}=1-\frac{16}{27}=0.407, \\
& \lambda_{33}=\frac{\left.\mid \mathrm{POS}_{2}\right\}}{|U|}-\frac{\operatorname{POS}(B)}{|U|}=1-\frac{16}{27}=0.407 .
\end{aligned}
$$

Step 6. Build a correlation matrix.

According to the above analysis, build the correlation matrix between consumer demand $\left(\mathrm{CR}_{1}, \mathrm{CR}_{2}\right.$, and $\left.\mathrm{CR}_{3}\right)$ and technical characteristics $\left(\mathrm{TC}_{1}, \mathrm{TC}_{2}\right.$, and $\left.\mathrm{TC}_{3}\right)$ :

$$
R M=\left(\lambda_{i j}\right)_{j=1,2,3}^{i=1,2,3}=\left[\begin{array}{ccc}
0.148 & 0.630 & 0.259 \\
0.556 & 0.333 & 0 \\
0 & 0.407 & 0.407
\end{array}\right]
$$

Step 7. Calculate the basic importance of technical characteristics.

The basic importance of technical characteristics can be calculated according to formula (4), as shown in Table 5.

5.2. TOPSIS Correction Calculation of Basic Importance of Technical Characteristics. When enterprising in the choice of technical characteristics, in addition to taking into account the basic importance dictated by consumer demand, other factors such as technical characteristics of configuration costs, technology maturity, and time commitment should also be considered. 
TABle 3: Good texture $\left(\mathrm{CR}_{2}\right)$ decision table.

\begin{tabular}{ccccccccccccccc}
\hline$U$ & $\mathrm{TC}_{1}$ & $\mathrm{TC}_{2}$ & $\mathrm{TC}_{3}$ & $\mathrm{CR}_{2}$ & $U$ & $\mathrm{TC}_{1}$ & $\mathrm{TC}_{2}$ & $\mathrm{TC}_{3}$ & $\mathrm{CR}_{2}$ & $U$ & $\mathrm{TC}_{1}$ & $\mathrm{TC}_{2}$ & $\mathrm{TC}_{3}$ & $\mathrm{CR}_{2}$ \\
\hline 1 & 1 & 1 & 1 & 1 & 10 & 2 & 1 & 1 & 2 & 19 & 3 & 1 & 1 \\
2 & 1 & 1 & 2 & 1 & 11 & 2 & 1 & 2 & 2 & 20 & 3 & 1 & 2 \\
3 & 1 & 1 & 3 & 1 & 12 & 2 & 1 & 3 & 2 & 21 & 3 & 1 & 3 & 2 \\
4 & 1 & 2 & 1 & 1 & 13 & 2 & 2 & 1 & 2 & 22 & 3 & 2 & 1 & 3 \\
5 & 1 & 2 & 2 & 1 & 14 & 2 & 2 & 2 & 2 & 23 & 3 & 2 & 2 & 3 \\
6 & 1 & 2 & 3 & 1 & 15 & 2 & 2 & 3 & 2 & 24 & 3 & 2 & 3 \\
7 & 1 & 3 & 1 & 2 & 16 & 2 & 3 & 1 & 3 & 25 & 3 & 3 & 1 & 3 \\
8 & 1 & 3 & 2 & 2 & 17 & 2 & 3 & 2 & 3 & 26 & 3 & 3 & 2 & 3 \\
9 & 1 & 3 & 3 & 2 & 18 & 2 & 3 & 3 & 3 & 27 & 3 & 3 & 3 \\
\hline
\end{tabular}

TABLe 4: Responsive $\left(\mathrm{CR}_{3}\right)$ decision table.

\begin{tabular}{cccccccccccccccc}
\hline$U$ & $\mathrm{TC}_{1}$ & $\mathrm{TC}_{2}$ & $\mathrm{TC}_{3}$ & $\mathrm{CR}_{3}$ & $U$ & $\mathrm{TC}_{1}$ & $\mathrm{TC}_{2}$ & $\mathrm{TC}_{3}$ & $\mathrm{CR}_{3}$ & $U$ & $\mathrm{TC}_{1}$ & $\mathrm{TC}_{2}$ & $\mathrm{TC}_{3}$ & $\mathrm{CR}_{3}$ \\
\hline 1 & 1 & 1 & 1 & 1 & 10 & 2 & 1 & 1 & 1 & 19 & 3 & 1 & 1 \\
2 & 1 & 1 & 2 & 1 & 11 & 2 & 1 & 2 & 1 & 20 & 3 & 1 & 2 & 1 \\
3 & 1 & 1 & 3 & 2 & 12 & 2 & 1 & 3 & 2 & 21 & 3 & 1 & 3 & 2 \\
4 & 1 & 2 & 1 & 1 & 13 & 2 & 2 & 1 & 1 & 22 & 3 & 2 & 1 & 1 \\
5 & 1 & 2 & 2 & 2 & 14 & 2 & 2 & 2 & 1 & 23 & 3 & 2 & 2 & 2 \\
6 & 1 & 2 & 3 & 2 & 15 & 2 & 2 & 3 & 3 & 24 & 3 & 2 & 3 \\
7 & 1 & 3 & 1 & 2 & 16 & 2 & 3 & 1 & 2 & 25 & 3 & 3 & 1 & 2 \\
8 & 1 & 3 & 2 & 2 & 17 & 2 & 3 & 2 & 3 & 26 & 3 & 3 & 2 & 3 \\
9 & 1 & 3 & 3 & 3 & 18 & 2 & 3 & 3 & 3 & 27 & 3 & 3 & 3 \\
\hline
\end{tabular}

Table 5: The basic importance of technical characteristics.

\begin{tabular}{lccr}
\hline Technical characteristics & Shell material $\mathrm{TC}_{1}$ & Processor performance $\mathrm{TC}_{2}$ & Operating system performance $\mathrm{TC}_{3}$ \\
\hline Basic importance & 0.235 & 0.457 & 0.222 \\
\hline
\end{tabular}

TABLE 6: The weight of each attributes.

\begin{tabular}{lcccc}
\hline Factors & Configuration cost & Maturity & Time investment & Basic importance \\
\hline Weight & 0.286 & 0.143 & 0.214 & 0.357 \\
\hline
\end{tabular}

TABle 7: Configuration cost.

\begin{tabular}{lccr}
\hline Technical characteristics & Shell material $\mathrm{TC}_{1}$ & Processor performance $\mathrm{TC}_{2}$ & Operating system performance $\mathrm{TC}_{3}$ \\
\hline Configuration cost & 0.236 & 0.418 & 0.346 \\
\hline
\end{tabular}

Step 1. Calculate the weight of each influencing factor. Set the first influencing factor is configuration cost, the second one is maturity, the third one is time investment, the fourth one is basic importance, and obtain the relative weight of each influencing factors, as shown in Table 6.

Step 2. Construct a standardized decision matrix.

The members of the house quality project team also evaluate the various factors for different technical characteristics. After the formalization of (11), the evaluation results are shown in Tables 7-9.

According to the above table, after formula (13) is weighted, add the basic importance of technical characteristics to get the weighted rule decision table, as shown in Table 10.
Step 3. Determine the ideal solution and negative ideal solution.

Considering four factors of technical characteristics, configuration cost and time investment should be costbased attributes; the maturity and the basic importance of technology should be efficiency-based attributes. Calculate the ideal and negative ideal solutions according to formulas (14) and (15).

The ideal solution $x^{+}$is $(0.044,0.060,0.064,0.098)$; the negative ideal solution $x^{-}$is $(0.122,0.034,0.074,0.048)$.

Step 4. Calculate the distance between each factor and ideal solution and negative ideal solution.

Calculate the distance between each factor and ideal solution and negative ideal solution according to formulas (16) and (17). 
TABle 8: Maturity.

\begin{tabular}{lccr}
\hline Technical characteristics & Shell material $\mathrm{TC}_{1}$ & Processor performance $\mathrm{TC}_{2}$ & Operating system performance $\mathrm{TC}_{3}$ \\
\hline Maturity & 0.427 & 0.235 & 0.338 \\
\hline
\end{tabular}

TABLE 9: Time investment.

\begin{tabular}{lccr}
\hline Technical characteristics & Shell material $\mathrm{TC}_{1}$ & Processor performance $\mathrm{TC}_{2}$ & Operating system performance $\mathrm{TC}_{3}$ \\
\hline Time investment & 0.178 & 0.523 & 0.299 \\
\hline
\end{tabular}

TABle 10: The weighted rule decision table.

\begin{tabular}{lcccc}
\hline Attributes technical characters & Configuration cost & Maturity & Time investment & Basic importance \\
\hline Shell material $\mathrm{TC}_{1}$ & 0.067 & 0.060 & 0.074 & 0.084 \\
Processor performance $\mathrm{TC}_{2}$ & 0.122 & 0.034 & 0.072 & 0.098 \\
Operating system performance $\mathrm{TC}_{3}$ & 0.051 & 0.057 & 0.064 & 0.048 \\
\hline
\end{tabular}

TABLE 11: Technical characteristics of TOPSIS correction results.

\begin{tabular}{lccc}
\hline & $\begin{array}{c}\text { The distance to the ideal solution } \\
d_{i}^{+}\end{array}$ & $\begin{array}{c}\text { The distance to the negative ideal } \\
\text { solution } d_{i}^{-}\end{array}$ & $\begin{array}{c}\text { Relative approximation } \\
C_{i}^{*}\end{array}$ \\
\hline Shell material $\mathrm{TC}_{1}$ & 0.029 & 0.071 & 0.710 \\
Processor performance $\mathrm{TC}_{2}$ & 0.083 & 0.050 & 0.376 \\
Operating system performance & 0.051 & 0.090 & 0.638 \\
TC $_{3}$ & & 0.03 & 0 \\
\hline
\end{tabular}

The distance to the ideal solution $\left(d_{i}^{+}\right)$is $(0.029,0.083,0.051)$ and to the negative ideal solution $\left(d_{i}^{-}\right)$is $(0.071,0.050,0.090)$.

Step 5. Calculate the importance of each technical characteristic that TOPSIS revised.

The importance of technical characteristic that TOPSIS revised can be obtained by calculating the relative approximation; according to formula (18), the calculation results are shown in Table 11 . It can be seen that the shell material is most important, and the processor performance is the least important.

\section{Conclusion}

This paper presents a new method to calculate the importance of technical characteristics. This method can use the rough set algorithm to establish the correlation matrix between consumer demand and technical characteristics to calculate the basic importance of technical characteristics, determine the weight of each influencing factor through the least square method, and use the TOPSIS multiattribute decision model to modify the basic importance of technical characteristics. The advantages of this method are as follows:

(1) In this method, the combination of different technical characteristics constitutes the object; the set of technical characteristics constitutes the set of conditional attributes, and the consumer demand is the set of decision attributes to construct the decision system. According to the idea of relative positive domain of rough set, the relationship between consumer demand and technical characteristics is established, and the correlation matrix between consumer demand and technical characteristics is established to calculate the basic importance of technical characteristics. This method not only enhances the objectivity of establishing correlation matrix but also improves the accuracy of calculating the importance of technical characteristics.

(2) In the decision-making of the importance of technical characteristics, this method not only considers the needs of consumers but also considers factors such as technology input cost, time input cost, and technology maturity. It breaks through the limitation of traditional methods only considering consumer factors.

(3) In the case analysis, the method takes into account the influence of factors such as product research and development $(R \& D)$ time, product $R \& D$ investment amount, and human resource consumption. To a certain extent, this method solves the fuzziness and uncertainty of technical characteristics. Enterprises can make more reasonable choice and configuration of technical characteristics in the fuzzy front-end design of product innovation.

However, the research of this paper is still in the initial stage. The following work aims to apply this method to more fuzzy front-end design of enterprise product innovation. We believe that, with the accumulation of practical application, the practicability and rationality of this method will be improved. 


\section{Data Availability}

No data were used to support this study.

\section{Conflicts of Interest}

The authors declare that they have no conflicts of interest.

\section{Acknowledgments}

The authors thank the scholars who have done research in the field of product innovation and design and who have provided the theoretical basis for their articles.

\section{References}

[1] R. Vongvit, N. Kongprasert, T. Fournaise, and T. Collange, "Integration of fuzzy-QFD and TRIZ methodology for product development," in Proceedings of the 2017 3rd International Conference on Control, Automation and Robotics (ICCAR), Nagoya, Japan, April 2017.

[2] X. Z. Liu, "A design process model of integrated morphological matrix and conflict resolving principles," Journal of Zhejiang University (Engineering Science), vol. 46, no. 12, pp. 2243-2251, 2012.

[3] Y. Chu and H. Ren, "Product requirement analysis based on the improved house of quality," in Proceedings of the 2015 IEEE International Conference on Grey Systems and Intelligent Services (GSIS), Leicester, UK, August 2015.

[4] X. Wang, H. Fang, and W. Song, "Technical attribute prioritisation in QFD based on cloud model and grey relational analysis," International Journal of Production Research, no. 1, pp. 1-18, 2019.

[5] L.-K. Chan and M.-L. Wu, "Quality function deployment: a comprehensive review of its concepts and methods," Quality Engineering, vol. 15, no. 1, pp. 23-35, 2002.

[6] K. Sonam and S. Jitendra, "From conception to creationquality function deployment in health sector," Mathematics and Computers in Contemporary Science, pp. 84-89, 2013.

[7] C. F. Yuan, "Approach of customer requirement analysis based on requirement element and improved HOQ in product configuration design," Journal of Software, vol. 7, no. 3, pp. 691-698, 2012.

[8] J. S. L. Lam and J. Dai, "Environmental sustainability of logistics service provider: an ANP-QFD approach," The International Journal of Logistics Management, vol. 26, no. 2, pp. 313-333, 2015.

[9] O. E. Nadiye and M. A. Omid, "Quality function deployment: more than a design tool," International Journal of Quality and Service Sciences, vol. 11, no. 2, pp. 144-166, 2019.

[10] J. Huang, X. Y. You, H. C. Liu, and S. L. Si, "New approach for quality function deployment based on proportional hesitant fuzzy linguistic term sets and prospect theory," International Journal of Production Research, vol. 57, no. 5, pp. 1283-1299, 2019.

[11] K. G. Fatm and K. Cengiz, "A novel spherical fuzzy QFD method and its application to the linear delta robot technology development," Engineering Applications of Artificial Intelligence, vol. 2020, no. 87, Article ID 103348.

[12] S. W. Hsiao, H. H. Lin, and Y. C. Ko, "Application of grey relational analysis to decision-making during product development," EURASIA Journal of Mathematics Science and Technology Education, vol. 13, no. 6, pp. 2581-2600, 2017.
[13] M. Tavana, M. Yazdani, and D. Di Caprio, “An application of an integrated ANP-QFD framework for sustainable supplier selection," International Journal of Logistics Research and Applications, vol. 20, no. 3, pp. 254-275, 2017.

[14] L. Q. Dat, T. T. Phuong, H.-P. Kao, S.-Y. Chou, and P. V. Nghia, "A new integrated fuzzy QFD approach for market segments evaluation and selection," Applied Mathematical Modelling, vol. 39, no. 13, pp. 3653-3665, 2015.

[15] K. Gotzamani, A. Georgiou, A. Andronikidis, K. Kamvysi, and V. D. W. Ton, "Introducing multivariate Markov modeling within QFD to anticipate future customer preferences in product design," International Journal of Quality \& Reliability Management, vol. 35, no. 3, pp. 762-778, 2018.

[16] O. S. Çevik, G. Büyüközkan, B. Ztayşi, and C. Kahraman, “A new hesitant fuzzy QFD approach: an application to computer workstation selection," Applied Soft Computing, vol. 46, pp. 1-16, 2016.

[17] D. Pamučar, I. Petrovic, and G. Cirovic, "Modification of the best-worst and MABAC methods: a novel approach based on interval-valued fuzzy-rough numbers," Expert Systems with Applications, vol. 91, pp. 89-106, 2018.

[18] S. Vinodh, V. Kamala, and K. Jayakrishna, "Integration of ECQFD, TRIZ, and AHP for innovative and sustainable product development," Applied Mathematical Modelling, vol. 38, no. 11-12, pp. 2758-2770, 2014.

[19] X. Wei-Guo and M. Chuan-Min, "Prioritizing technical requirements in QFD by integrating grey relational analysis method and analytic network process approach," Grey Systems: Theory and Application, vol. 5, no. 1, pp. 117-126, 2013.

[20] L. Yu, L. Wang, and Y. Bao, "Technical attributes ratings in fuzzy QFD by integrating interval-valued intuitionistic fuzzy sets and CHOQuet integral," Soft Computing, vol. 22, no. 6, pp. 2015-2024, 2016.

[21] J. S. L. Lam and K.-h. Lai, "Developing environmental sustainability by ANP-QFD approach: the case of shipping operations," Journal of Cleaner Production, vol. 105, pp. $275-284,2015$.

[22] S. Zaim, M. Sevkli, H. Camgöz-Akdağ, O. F. Demirel, A. Yesim Yayla, and D. Delen, "Use of ANP weighted crisp and fuzzy QFD for product development," Expert Systems with Applications, vol. 41, no. 9, pp. 4464-4474, 2014.

[23] T. Sang-Bing, C. Kuan-Yu, Z. Hongrui et al., "Using a mixed model to explore evaluation criteria for bank supervision: a banking supervision law perspective," PLoS One, vol. 11, no. 12, Article ID e0167710, 2016.

[24] T. Park and K.-J. Kim, "Determination of an optimal set of design requirements using house of quality," Journal of $\mathrm{Op}$ erations Management, vol. 16, no. 5, pp. 569-581, 1998.

[25] K.-J. Kim, H. Moskowitz, A. Dhingra, and G. Evans, "Fuzzy multicriteria models for quality function deployment," $E$ uropean Journal of Operational Research, vol. 121, no. 3, pp. 504-518, 2000.

[26] R. Y. K. Fung, Y. Chen, L. Chen, and J. Tang, "A fuzzy expected value-based goal programing model for product planning using quality function deployment," Engineering Optimization, vol. 37, no. 6, pp. 633-645, 2005.

[27] W. Jia, Z. Liu, Z. Lin, C. Qiu, and J. Tan, "Quantification for the importance degree of engineering characteristics with a multi-level hierarchical structure in qfd," International Journal of Production Research, vol. 54, no. 6, pp. 1-23, 2015.

[28] L.-H. Chen, W.-C. Ko, and C.-Y. Tseng, "Fuzzy approaches for constructing house of quality in qfd and its applications: a group decision-making method," IEEE Transactions on Engineering Management, vol. 60, no. 1, pp. 77-87, 2013. 
[29] C. K. Wong, Y. Chen, H. Bai, and D. S. K. Chan, "A methodology of determining aggregated importance of engineering characteristics in QFD," Computers \& Industrial Engineering, vol. 53, no. 4, pp. 667-679, 2007.

[30] J. Liu, Y. Chen, J. Zhou, and X. Yi, “An exact expected valuebased method to prioritize engineering characteristics in fuzzy quality function deployment," International Journal of Fuzzy Systems, vol. 18, no. 4, pp. 630-646, 2015.

[31] P. Zheng and S. Xie, "A rough set based fuzzy axiomatic design approach in evaluating customer-centric design alternatives," in Proceedings of the 2015 IEEE International Conference on Industrial Engineering and Engineering Management (IEEM), pp. 544-548, Singapore, December 2015.

[32] W. Song, X. Ming, and Y. Han, "Prioritising technical attributes in QFD under vague environment: a rough-grey relational analysis approach," International Journal of Production Research, vol. 52, no. 18, pp. 5528-5545, 2014.

[33] E. E. Karsak, "Fuzzy multiple objective decision making approach to prioritize design requirements in quality function deployment," International Journal of Production Research, vol. 42, no. 18, pp. 3957-3974, 2004.

[34] J. Wang, "Fuzzy outranking approach to prioritize design requirements in quality function deployment," International Journal of Production Research, vol. 37, no. 4, pp. 899-916, 1999.

[35] C. H. Han, J. K. Kim, and S. H. Choi, "Prioritizing engineering characteristics in quality function deployment with incomplete information: a linear partial ordering approach," International Journal of Production Economics, vol. 91, no. 3, pp. 235-249, 2004.

[36] E. E. Karsak, S. Sozer, and S. E. Alptekin, "Product planning in quality function deployment using a combined analytic network process and goal programming approach," Computers \& Industrial Engineering, vol. 44, no. 1, pp. 171-190, 2003.

[37] Y. Li, J. Tang, X. Luo, and J. Xu, "An integrated method of rough set, Kano's model and AHP for rating customer requirements' final importance," Expert Systems with Applications, vol. 36, no. 3, pp. 7045-7053, 2009.

[38] S. Andhalkar and B. F. Momin, "Rough set theory and its extended algorithms," in Proceedings of the 2018 Second International Conference on Intelligent Computing and Control Systems (ICICCS), pp. 1434-1438, Madurai, India, 2018.

[39] Y.-L. Li, J.-F. Tang, K.-S. Chin, Y. Han, and X.-G. Luo, “A rough set approach for estimating correlation measures in quality function deployment," Information Sciences, vol. 189, pp. 126-142, 2012.

[40] C. Zhang, D. Y. Li, and X. P. Kang, "Neutrosophic fusion of rough set theory: an overview," Computers in Industry, vol. 115, 2020.

[41] M. F. D. Bagus, "Evaluations of parameters importance based on human sensory data and bayesian rough set model," in Proceedings of the2018 IEEE 9th International Conference on Mechanical and Intelligent Manufacturing Technologies (ICMIMT), pp. 100-104, Cape Town, South Africa, February 2018.

[42] T. Özcan, N. Çelebi, and Ş. Esnaf, "Comparative analysis of multi-criteria decision making methodologies and implementation of a warehouse location selection problem," Expert Systems with Applications, vol. 38, no. 8, pp. 9773-9779, 2011.

[43] C. L. Hwang and K. P. Yoon, Fuzzy Multiple Attribute Decision Making: Methods and Applications, Springer-Verlag, New York, NY, USA, 1981
[44] P. Chen, "Effects of normalization on the entropy-based TOPSIS method," Expert Systems with Applications, vol. 136, pp. 33-41, 2019.

[45] V. Jain and S. A. Khan, "Reverse logistics service provider selection: A TOPSIS-QFD approach," in Proceedings of the 2016 IEEE International Conference on Industrial Engineering and Engineering Management (IEEM), pp. 803-806, Bali, Indonesia, December 2016.

[46] G. Dwivedi, R. K. Srivastava, and S. K. Srivastava, "A generalised fuzzy TOPSIS with improved closeness coefficient," Expert Systems with Applications, vol. 96, pp. 185-195, 2018.

[47] J. Tang, R. Y. K. Fung, B. Xu, and D. Wang, "A new approach to quality function deployment planning with financial consideration," Computers \& Operations Research, vol. 29, no. 11, pp. 1447-1463, 2002.

[48] C. Jaeho, C. Jaeyoul, K. Inhan et al., "Preference evaluation system for construction products using QFD-TOPSIS logic by considering trade-off technical characteristics," Mathematical Problems in Engineering, vol. 2017, Article ID 9010857, 15 pages, 2017.

[49] C.-N. Liao and H.-P. Kao, "An evaluation approach to logistics service using fuzzy theory, quality function development and goal programming," Computers \& Industrial Engineering, vol. 68, pp. 54-64, 2014.

[50] J. M. Xie and Q. Qin, "Decision-making model of clustering consumer demand in innovation process based on rough sets," Statistics \& Decision, vol. 23, no. 12, pp. 78-80, 2015.

[51] S.-H. Su and Z.-J. Xu, "The connectedness relative to a subbase for the L-fuzzy topology," Advances in Intelligent and Soft Computing, Springer, Berlin Germany, pp. 679-686, 2009. 